Fourth International Conference on Sustainable Construction Materials and Technologies http://www.claisse.info/Proceedings.htm

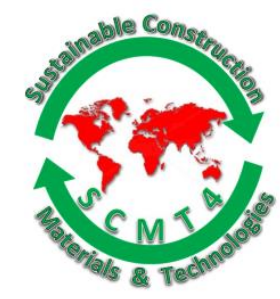

SCMT4

Las Vegas, USA, August 7-11, 2016

\title{
Ceramic Waste Powder as an Ingredient to Sustainable Concrete
}

\author{
Dima M. Kanaan ${ }^{1 a}$, and Amr S. EL-Dieb*1b \\ ${ }^{1}$ Civil and Environmental Engineering Department, United Arab Emirates University, UAE. \\ ${ }^{1 a}$ E-mail: $200734835 @$ @aeu.ac.ae>, ${ }^{1 a}$ E-mail: 〈amr.eldieb@uaeu.ac.ae〉.
}

\begin{abstract}
Concrete industry plays a major role in sustainable development. Several industrial solid wastes have properties which suits concrete; the most popular ones are blast furnace slag, fly ash and silica fume which are currently used as supplementary cementitious materials (SCM) in concrete and are common in today's concrete industry. The use of SCM in concrete has twofold advantages; first is clear and immediate environmental benefit of using a material that was once a landfill and second reducing some negative effects of cement production mainly high energy consumption and emission of greenhouse gas. Therefore, there are potentials to increase the solid waste recycling by investigating the possibility to use other industrial solid wastes in concrete production.
\end{abstract}

Ceramic waste powder (CWP) is produced during the polishing process of ceramic tiles and then dumped in landfills can cause soil, air and groundwater pollution leading to a serious environmental problem. Utilization of CWP will help to protect the environment, achieve sustainable development and become a cheaper but almost equivalent to other SCM already used in the concrete industry. In this study CWP is investigated as an alternative ingredient in making concrete as SCM. The study focuses on studying the properties of fresh and hardened concrete mixtures (i.e. slump, slump loss, compressive strength and drying shrinkage) besides the durability features as evaluated from the RCPT test for concrete mixtures incorporating CWP as SCM with different weight replacement levels (1020-30-40\%). It is found that CWP improves slump retention, moderately increases setting time and compressive strength. CWP can be utilized effectively as SCM in concrete which will result in an effective way for solid waste management and sustainable development.

\section{INTRODUCTION}

In response to the expanding interest in sustainable development, researchers all over the world were encouraged to search and utilize alternative resources that are more sustainable. The construction industry has been looking for techniques that might effectively decrease the elevated energy and environmental impacts of cement manufacturing. Concrete drew the attention to the probability of using industrial solid wastes in its manufacture. This would decrease the consumption of raw resources and required energy in addition help in saving the exhausted landfills. The Production of 1 ton of Portland cement generates around an equal amount of $\mathrm{CO}_{2}$ [Sadek et al. 2014]. This contributes to around 5-8\% of the annual global greenhouse gas emissions to the atmosphere [Najim et al. 2016]. The use of industrial solid wastes in concrete to partially substitute cement will lead to a sustainable concrete and a greener environment. Several materials 
were used to replace cement partially and/or completely which is considered an efficient solution to the above mentioned problems such as fly ash, slag which are used as supplementary cementitious materials (SCM) in daily concrete production. With Abu Dhabi development plans, there will be an increasing demand on cement and therefore an expected increase in $\mathrm{CO}_{2}$ emission which will have negative impact on the environment and the society.

The negative impact of industrial solid waste have on the environment has led researchers [Halicka et al. 2013] to examine the use of ceramic sanitary ware waste as coarse and fine concrete aggregate. It was concluded that ceramic waste aggregates are feasible to be used in concrete manufacture. A recent research work was carried by [Rahhal et al. 2014] and focused on the utilization of ceramic waste (CW) as replacement of Portland cement. The investigation studied the use of two ceramic waste types from different sources. CW was incorporated with cement by $(8,16,24,32$, and $40 \%)$ by weight of cement. Investigation findings showed that $\mathrm{CW}$ has pozzolanic activity which developed the performance of investigated concrete.

Ceramic tiles are widely used in most structures; its production generates ceramic waste powder (CWP) during the polishing process of ceramic tiles. In Abu Dhabi, the average CWP produced from one company is estimated at 10,000 tons/year. This brings a major challenge with respect to its environmental impact. On the other hand, it represents a good opportunity as an alternative concrete ingredient if it could be utilized in making concrete. The aim of this study is to investigate the CWP as an alternative ingredient in concrete mixtures replacing cement. The effect of incorporating CWP as partial cement replacement will be investigated on the fresh and hardened properties. Two strength grades 25 and $75 \mathrm{MPa}$ concrete mixtures are investigated. The durability performance of the hardened concrete is evaluated as well.

\section{EXPERIMENTAL METHODOLOGY}

This investigation includes two experimental phases. Phase one includes testing on the as received ceramic waste powder (CWP) material that will be used later in the study to find its properties and characteristics. Techniques like SEM were used to identify the specimen's surface topography. X-ray diffraction (XRD) and X-ray florescence (XRF) were used to determine the morphology and chemical composition of the CWP material. Several material properties were measured such specific surface area, particle size distribution and moisture content. Phase two focused on the utilization of ceramic waste powder material (CWP) partially replacing cement with different weight replacement levels $(0,10,20,30$ and 40$) \%$ by mass of cement. Two strength grades 25 and $75 \mathrm{MPa}$ concrete mixtures were investigated. The influence of ceramic waste powder (CWP) was investigated through performing several tests on fresh concrete (i.e. slump, slump loss and setting time) and hardened concrete (i.e. compressive strength, rapid chloride permeability test (RCPT), permeable voids and drying shrinkage).

\section{Materials}

Three materials were utilized in the concrete mixtures production identified as aggregate, cement and ceramic waste powder (CWP) with the incorporation of tap potable water and admixture when needed. Concrete mixtures were prepared using ordinary Portland cement (OPC). The OPC conforms to the ASTM C150 Type 1 and BS-EN197 CEM I. The specific surface area of cement was $388 \mathrm{~m}^{2} / \mathrm{kg}$. Coarse aggregates used in this investigation were natural crushed stones from Ras Al Khaima, UAE, with nominal sizes of (10 and 19) $\mathrm{mm}$ which were mixed in (1:1) by mass. The specific gravity was 2.65 while the absorption was about $1 \%$. For the concrete mixture M 75, only $10 \mathrm{~mm}$ aggregate was used. Two Fine aggregate types were used. Crushed natural sand brought from Ras Al Khaima, UAE, with a specific gravity of 2.63 and fineness modulus of 3.5, in addition to dune sand that brought from Al Ain area, UAE, with a specific gravity of 2.63 and fineness modulus of 0.9 .

In this investigation a polycarboxylic ether superplasticizer conforming to ASTM C494 Type G and ASTM C1017 Type II was used to produce concrete mixtures with grade $75 \mathrm{MPa}$. 


\section{Ceramic waste powder}

The ceramic waste powder used in this investigation was produced from the polishing process of final ceramic tiles in a factory located in Abu Dhabi, UAE. The original raw materials used in the production of ceramic tiles were: feldspar, ball clay, China clay and silica sand. Kaolin is the essential ingredient of most of the raw ingredients. Materials then were fired at a temperature of $1200{ }^{\circ} \mathrm{C}$ to produce the ceramic tiles which were polished at the final stage leading to the production of CWP.

The as received ceramic waste material was a wet powder as delivered from the factory. The delivered ceramic powder material was dried for 24 hours in an oven at $110{ }^{\circ} \mathrm{C}$. The average moisture content was about $36 \%$ by mass. After the drying procedure, many ceramic waste powder particles coagulated together and formed larger particles, which might be divided up manually by hand into powder particles. Then, the dried CWP material was ground to an average Blaine specific surface area (SSA) was $555 \mathrm{~m}^{2} / \mathrm{kg}$. More than 50\% of the CWP particles had size ranging between 7-9 $\mu \mathrm{m}$. The dried and grounded CWP were wellpreserved in air tight containers. Figure 1 presents the SEM micrographs of the grounded CWP. The CWP particles consist of irregular and angular particles similar to cement particles.
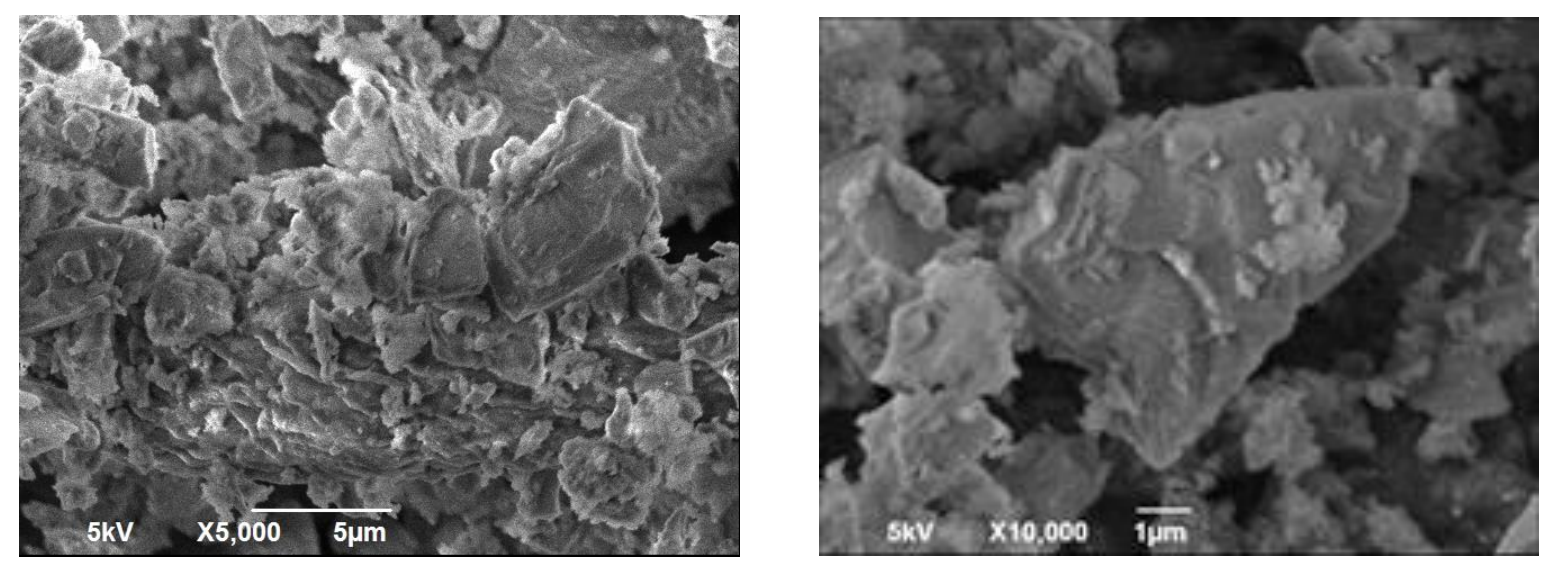

\section{Figure 1. SEM Images of Ceramic Waste Powder (CWP).}

Figure 2 shows the XRD of the CWP. The XRD analysis revealed that the predominant peaks were obviously noticed between 2 theta values of $20^{\circ}$ to $30^{\circ}$ which indicates the presence of quartz $\left(\mathrm{SiO}_{2}\right)$. The observed hump between $20^{\circ}$ to $30^{\circ}$ indicates the occurrence of an amorphous phase in the CWP material sample as per the test outcomes. Furthermore, the unleveled graph trend from 0 to $40^{\circ}$, might be an indication of amorphous phase in the CWP sample. The XRF chemical analysis is given in Table 1. The CWP is mainly composed of $\mathrm{SiO}_{2}$ and $\mathrm{Al}_{2} \mathrm{O}_{3}$ which represents more than $80 \%$

Table 1. Main Oxides of the CWP

\begin{tabular}{|l|c|c|c|c|c|c|c|c|}
\hline Oxide & $\mathrm{SiO}_{2}$ & $\mathrm{Al}_{2} \mathrm{O}_{3}$ & $\mathrm{Fe}_{2} \mathrm{O}_{3}$ & $\mathrm{CaO}$ & $\mathrm{MgO}$ & $\mathrm{KO}$ & $\mathrm{Na}_{2} \mathrm{O}$ & L.O.I. \\
\hline Mass \% & 67.51 & 16.92 & 0.75 & 1.33 & 1.82 & 1.31 & 4.80 & 2.54 \\
\hline
\end{tabular}




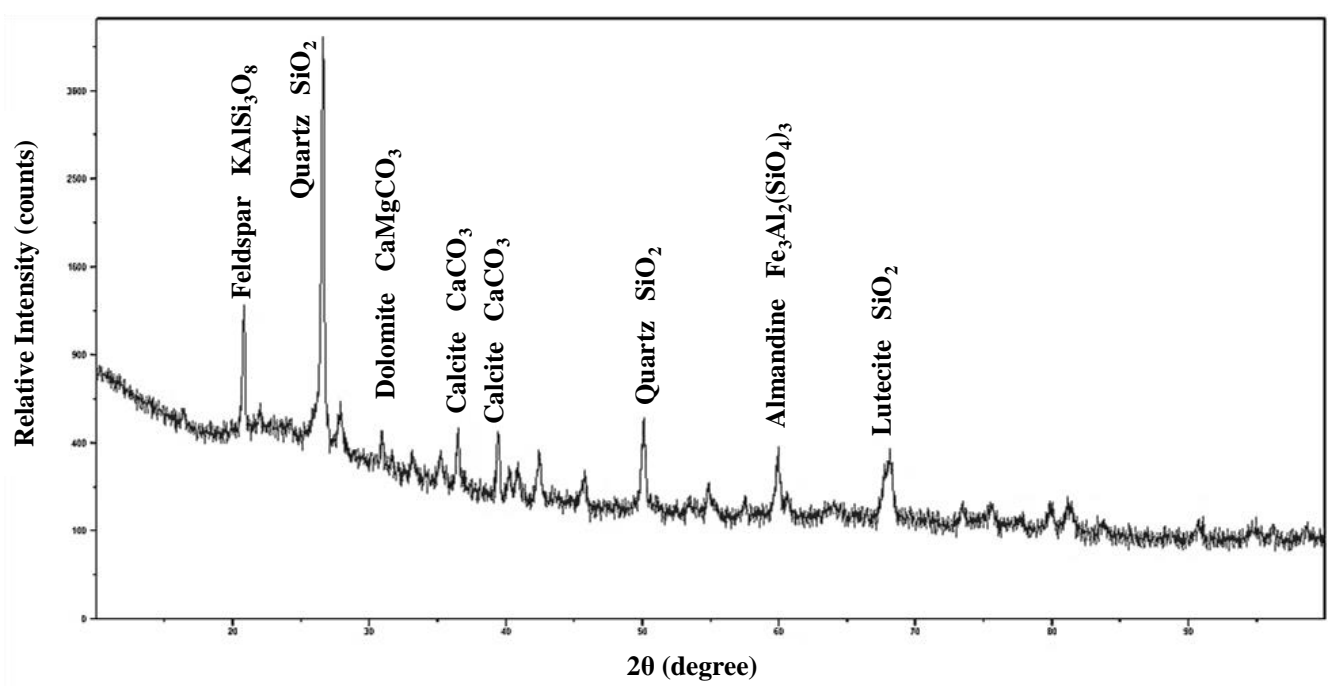

Figure 1. XRD Pattern of Ceramic Waste Powder (CWP).

Concrete mixtures proportions. Table 2 gives the proportions of the two strength grade concrete mixtures. For each strength grade ( 25 and 75 ) MPa, cement was partially replaced by CWP. Four weight replacement levels were studied (10, 20, 30 and 40\%). For the (25 and 75) MPa concrete mixtures, upon using CWP the weight of the aggregate was adjusted to preserve the volume of the mixture unchanged.

Table 2. Concrete Mixtures Proportions by Weight $\left(\mathrm{kg} / \mathrm{m}^{3}\right)$

\begin{tabular}{|c|c|c|c|c|c|c|}
\hline & & \multicolumn{2}{|c|}{ Fine Aggregate } & \multicolumn{2}{|c|}{ Coarse Aggregate } & \multirow{2}{*}{ Water Content } \\
\cline { 4 - 6 } Mixture Designation & \multirow{2}{*}{ Cement } & Sand & Dune & $10 \mathrm{~mm}$ & $20 \mathrm{~mm}$ & \\
\hline & & & & & & \\
\hline M 25 & 310 & 448 & 301 & 438 & 664 & 190 \\
\hline M 75 & 525 & 399 & 268 & 1022 & - & 177 \\
\hline
\end{tabular}

\section{RESULTS AND DISCUSSIONS}

Fresh concrete tests. Slump/Slump loss. Slump loss known as the drop in slump value with time after the initial contact between cement and water. Slump loss test was performed to identify the workability retention by measuring the slump value at different elapsed time intervals of 15 minutes. The mixture was mixed for 30 seconds before each slump measurement. The slump and slump loss results of the $25 \mathrm{MPa}$ concrete mixtures are shown in figure 3. From the results, initial slump value apparently decreases as the level of CWP replacement increases. This could be attributed to the high specific surface area of CWP which is 1.5 times that of the cement replaced. It is noted that for the mixture with the $10 \% \mathrm{CWP}$ replacement level, the effect of the high specific surface area of the CWP was not significant. The slump retention was improved as the replacement level increased up to $40 \%$. The retention time increased due to the fact that CWP has no hydraulic reaction and any pozzolanic reaction of the CWP is slow resulting in the availability of water in the mixture. 


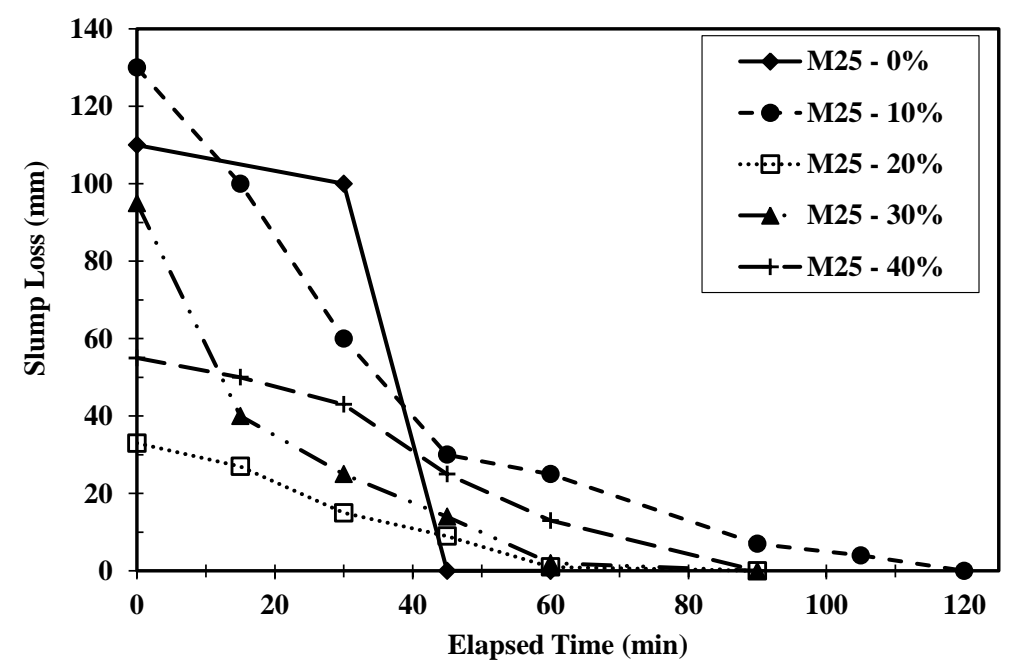

Figure 2. Slump/Slump Loss Results for M 25 Mixtures.

Figure 4 shows the slump/slump loss test results for all the $75 \mathrm{MPa}$ concrete mixtures. The workability of $75 \mathrm{MPa}$ CWP concretes and conventional concrete mixtures revealed a variable behavior for the slump and slump loss. This might be attributed to the inclusion of Type $G$ admixture in the mixtures. The effect of using different CWP replacement levels on the admixture dosage needs further investigations to understand the behavior of the fresh mixtures including CWP and admixture.

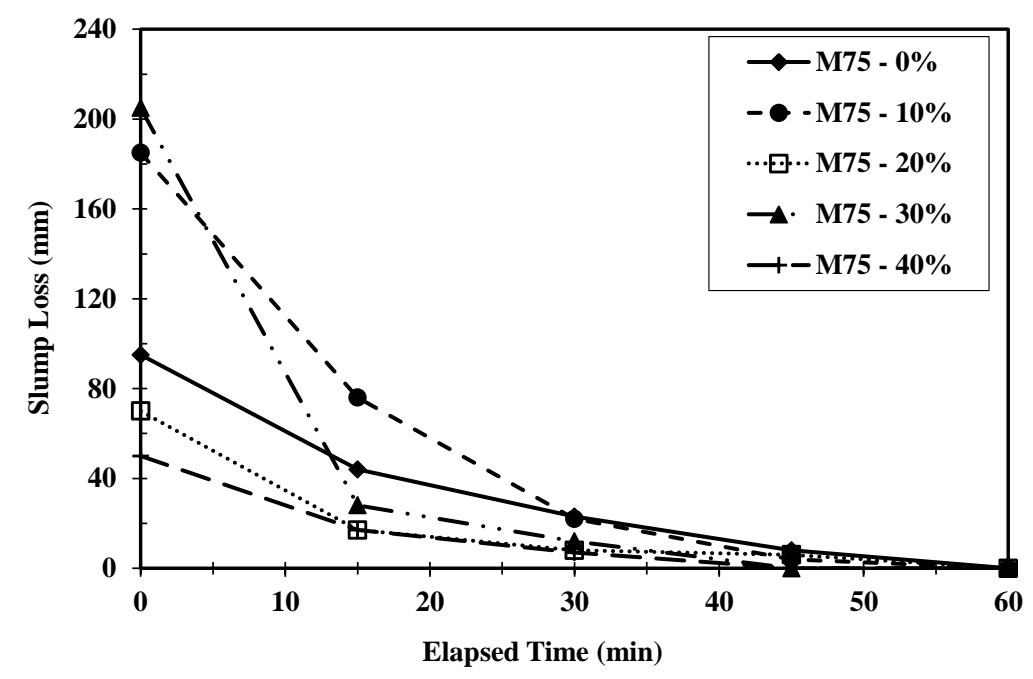

Figure 3. Slump/Slump Loss Results for M 75 Mixtures.

\section{Hardened concrete tests}

Compressive strength development. Figure 5 shows the change in the compressive strength results with age for the $25 \mathrm{MPa}$ mixtures incorporating different levels of CWP relative to the reference mixture with no CWP. M 25-0\% achieved average compressive strength values of 18.3, 25.7, 27.8 and 29.8 MPa for 7, 28, 56 and 90 days of age respectively. Overall, it was noted that mixtures with $10 \%$ replacement level of CWP showed improvement in the strength values at all ages. On the other hand, concretes with $20 \%$ up to 
$40 \%$ replacement level demonstrated lower strength development compared to the $10 \%$ CWP mixture. It was also noted that at 56 and 90 days of age, concretes including 10\% CWP expressed the highest strength increase. This can be attributed to the fine particles of CWP that might result in more effective packing especially around aggregates. Therefore, the development of compressive strength could mostly be the result of micro-filling effect and the pozzolanic reactivity of the CWP material at late ages.

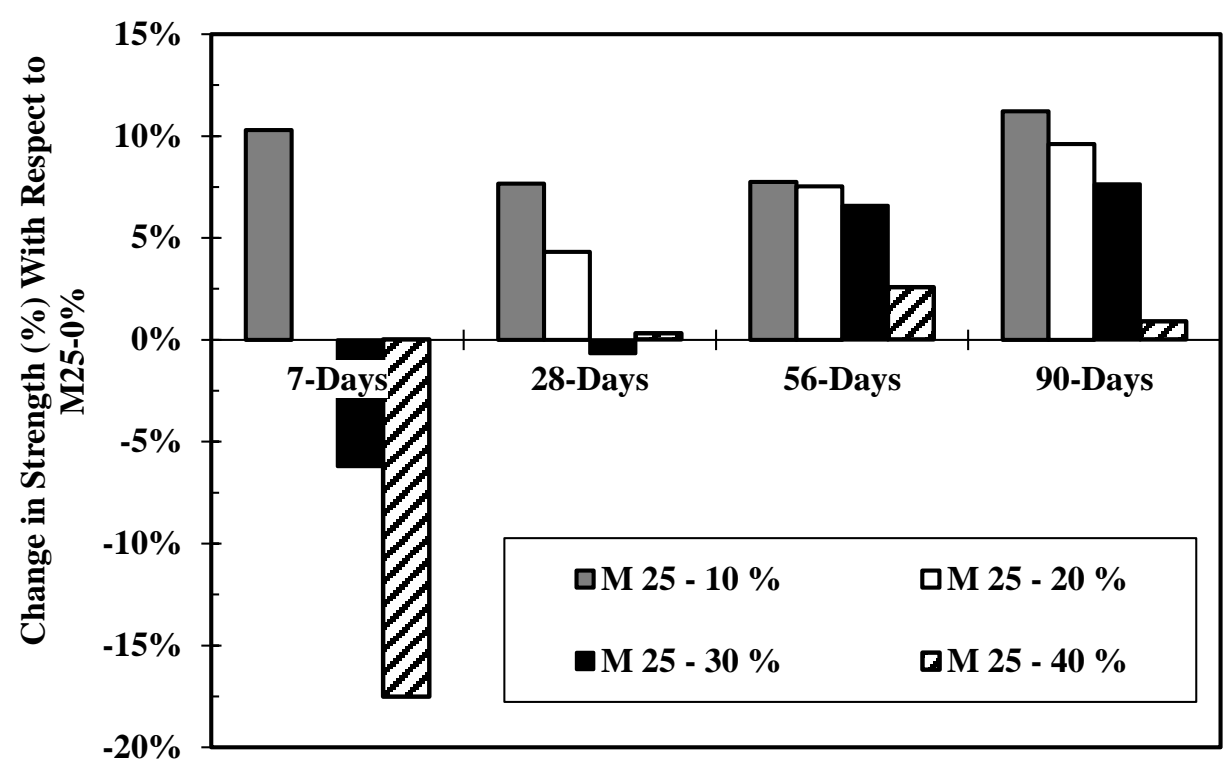

Figure 4. Change in Compressive Strength for M 25 Mixtures.

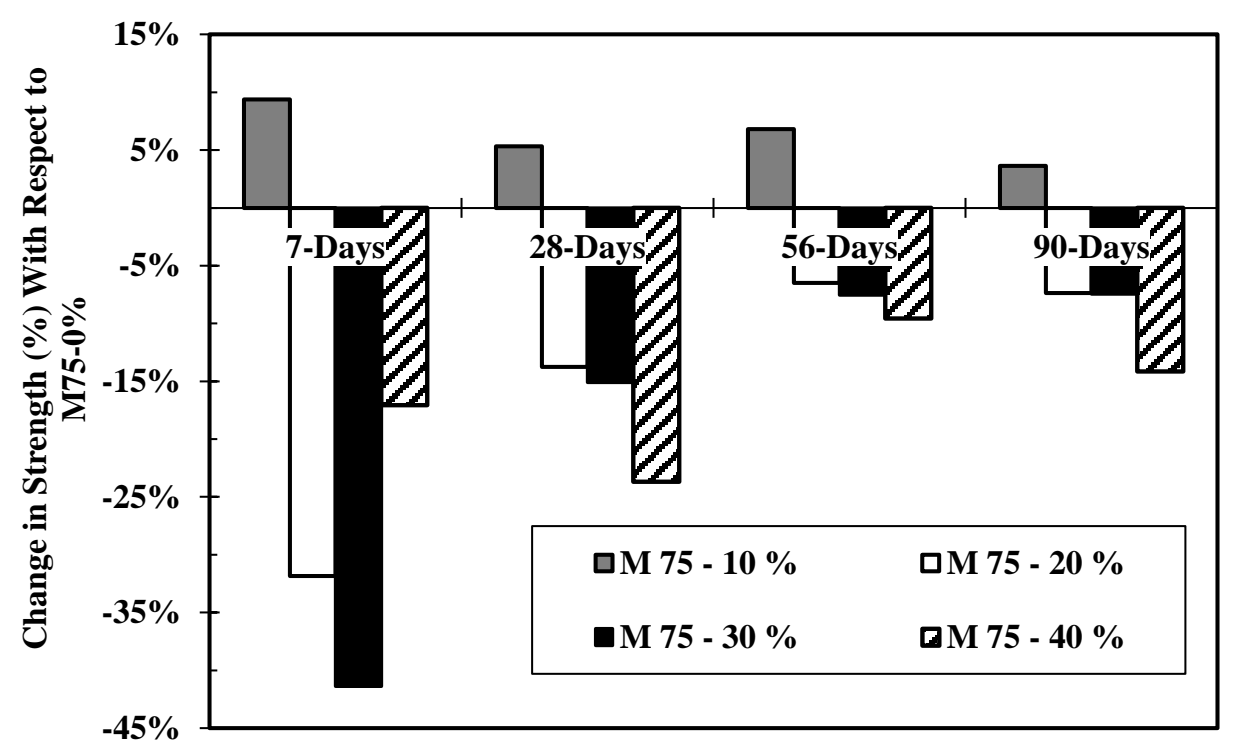

Figure 5. Change in Compressive Strength for M 75 Mixtures. 
The effect of CWP on the compressive strength development of the high performance $75 \mathrm{MPa}$ concrete mixtures at different ages is presented in Error! Reference source not found.. M 75-0\% achieved average compressive strength values of $73.2,80.0,82.0$ and $86.5 \mathrm{MPa}$ for $7,28,56$ and 90 days of curing respectively. According to the test results, as the CWP percentage increases above $10 \%$ replacement level, strength does not show any improvement. This could be accredited to the fact that for HPC mixtures the replacement levels resulted in significantly reducing the binder content. While for $10 \%$ replacement level the reduction was not significant to reduce the strength and the microfilling effect of CWP offset the reduction of the binder content. Also, as the CWP content increases in the mixtures, the free water content increases that resulted in adverse effect on the strength.

Rapid Chloride Permeability Test (RCPT). Figure 6 illustrates the RCPT test results for the $25 \mathrm{MPa}$ mixtures. The performance of the examined mixtures was compared to the reference concrete mixture after 28 and 90 days of curing as well as with the ASTM C1202 standards classifications. It was noticed that after 28 days of curing, the total passed charge in (coulombs) ranges between "Moderate" to "Very Low" as the CWP \% increases up to $40 \%$. Similarly, after 90 days of curing, the chloride ions permeability reduces sharply especially to "Very Low" chloride permeation especially for mixtures with CWP. This could be attributed to the densification of the microstructure and lower pores connectivity owing to the microfilling effect of CWP in addition to some pozzolanic activity.

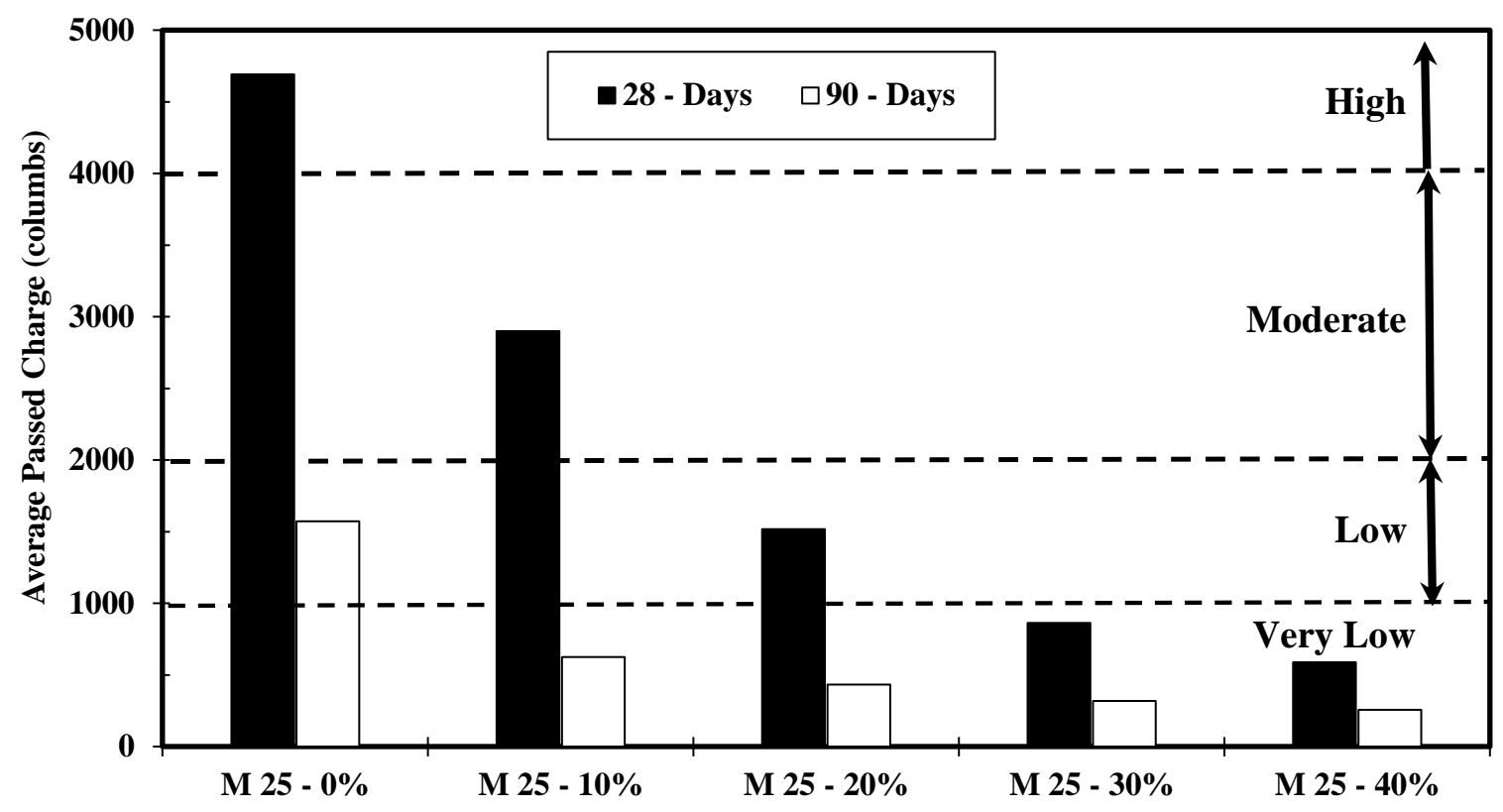

Figure 6. RCPT Results for M 25 Mixtures.

For all high performance concrete mixtures, $M 75$, the total passed charge is displayed in

Figure 7. It is observed that, the total charge passed for all concrete specimens varies between 0 and 1280 coulombs. These values rank the concrete mixtures as "Low" to "Very Low" chloride ions penetration. From the results, concrete mixtures with up to $40 \%$ CWP by mass showed a very high resistance to chloride penetration at 28 and 90 days of curing. The resistance to chloride penetration is significantly improved after the inclusion of CWP as a result of the high amount of fine particles in the mixtures leads to the densification of the microstructure and discontinuity of the porous network. Therefore, in contrast to the performance the CWP inclusion on strength development, the concrete durability with respect to chloride ion penetration is significantly improved. 
Permeable pores. Permeable pores were measured at 90 days of age according to ASTM C642. Table 3 shows the average measured permeable pores for M 25 and M 75 mixtures. It is noticed that for both concrete grades, the inclusion of CWP reduces the permeable pores and the reduction increases as the level of CWP replacement increases. The reduction for all mixtures ranges from $17 \%$ to $40 \%$. Reducing the pores will contribute to improving the concrete's durability characteristics especially when the pores connectivity is reduced as observed in the RCPT results.

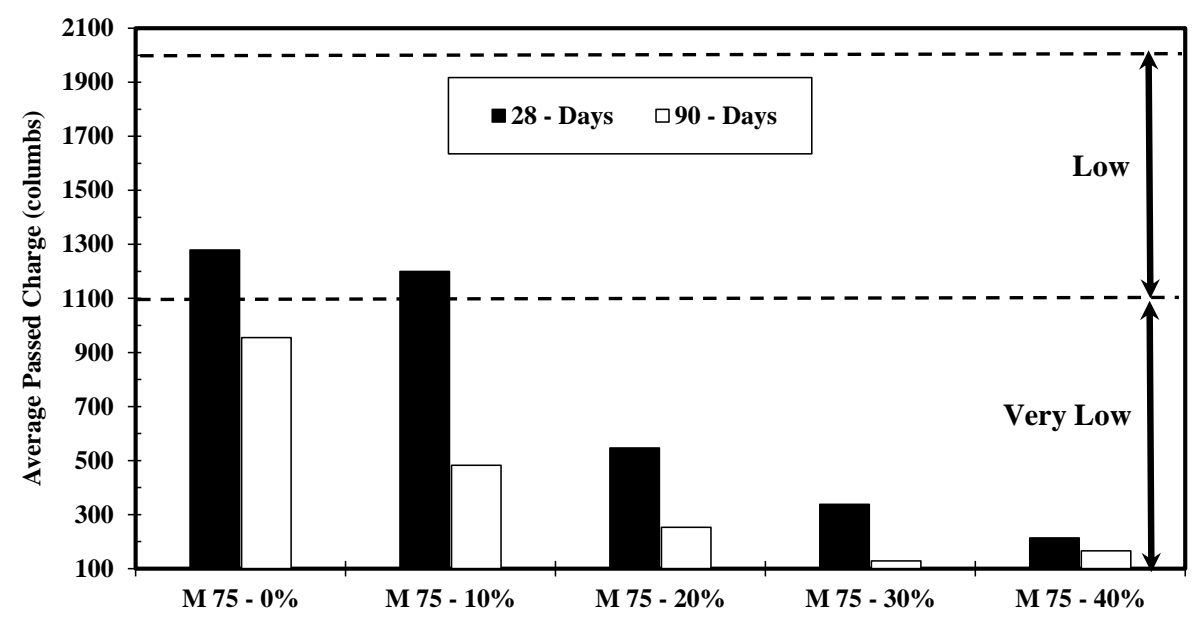

Figure 7. RCPT Results for M 75 Mixtures.

Table 3. Drying Shrinkage and Permeable Voids Results

\begin{tabular}{|c|c|c|}
\hline Mix I.D. & $\begin{array}{c}\text { Permeable } \\
\text { Voids \% }\end{array}$ & $\begin{array}{c}\text { Shrinkage } \\
\text { Strain at 120 } \\
\text { days }(\mu \varepsilon)\end{array}$ \\
\hline M 25-0 & 10.1 & 2608 \\
\hline M 25 - 10 & 8.4 & 2488 \\
\hline M 25 - 20 & 7.4 & 2817 \\
\hline M 25 - 30 & 7.0 & 1033 \\
\hline M 25 - 40 & 6.5 & 1859 \\
\hline
\end{tabular}

\begin{tabular}{|c|c|c|}
\hline Mix I.D. & $\begin{array}{c}\text { Permeable } \\
\text { Voids } \%\end{array}$ & $\begin{array}{c}\text { Shrinkage Strain at } 120 \\
\text { days }(\mu \varepsilon)\end{array}$ \\
\hline M 75 - 0 & 6.3 & 2567 \\
\hline M 75 - 10 & 5.1 & 2265 \\
\hline M 75 - 20 & 4.7 & 2808 \\
\hline M 75 - 30 & 4.1 & 1930 \\
\hline M 75 - 40 & 3.8 & 1869 \\
\hline
\end{tabular}

Drying shrinkage. Drying Shrinkage measurements were measured after 120 days as shown in Table 3. For concrete mixtures with and without CWP as replacement of cement, each presented value is the average of three readings. It can be noticed from the 25 and $75 \mathrm{MPa}$ mixtures that the drying shrinkage values decrease with the increase in CWP content. Since CWP has some pozzolanic reactivity characteristics, replacing cement with CWP would decrease the shrinkage vales as the replacement increases up to $40 \%$ due to the dilution effect compared to the reference concrete mixture without CWP. For the $25 \mathrm{MPa}$ mixtures, using CWP with replacement levels up to $40 \%$ leads to reducing the drying shrinkage values by from 5\% to $60 \%$ compared to the control mixture. As for the high performance concrete mixtures, M 75, the reduction in the drying shrinkage ranges from $12 \%$ to $27 \%$.

There is a correlation between the drying shrinkage results and the volume of permeable voids. As seen in Figures 7 and 8 and Table 3, the CWP has a major role in reducing the permeable pores and the connectivity of pores by improving the particle packing especially at the aggregate/paste interfacial zone. This helps the concrete mixtures with CWP to reduce the loss of water from inside specimens which is reflected on reducing the drying shrinkage. 


\section{CONCLUSION}

The main outcomes of the experimental investigation are:

- Used CWP included more than $80 \% \mathrm{SiO}_{2}$ and $\mathrm{Al}_{2} \mathrm{O}_{3}$. The CWP particles are similar to those of cement in shape. The fineness of CWP is 1.5 times that of the cement.

- Recycling of ceramic waste powder (CWP) and its usage as an alternative ingredient to replace cement in the concrete production is feasible and beneficial.

- Fresh concrete properties for the $25 \mathrm{MPa}$ mixtures showed that the use of ceramic waste powder in concrete mixtures improved its workability retention.

- For the concrete mixture M 75, the behavior of the fresh mixtures including CWP and Type G/Type 2 admixture was unclear and needs further investigation.

- Hardened concrete properties of $25 \mathrm{MPa}$ concrete mixtures included CWP exhibited an overall strength improvement all ages except for 7-days of age. The use of $10 \%$ CWP resulted in the highest strength improvement. With CWP replacement levels above $10 \%$ the strength improvement was lower. The development of compressive strength could be accredited to the microfilling ability and the pozzolanic reactivity of the CWP material.

- All HPC mixtures, M 75, with CWP above 10\% replacement level showed reduction in the strength values at all ages.

- The RCPT results and permeable pores values of all concrete mixtures made with CWP showed significant high resistance to chloride penetration as the substitution level was increased. The resistance to chloride ion penetration was considerably improved due to the development of less porous and discontinuous voids system owing to the microfilling effect of CWP in addition to some pozzolanic reaction.

- CWP replacement level decreased the measured 120 days drying shrinkage strains due to the dilution effect besides the filling of voids in mixtures by CWP particles.

- The level of CWP replacement to be used in the mixture depends on the main performance required, for example a level of $10 \%$ replacement is adequate for strength improvement while a level of $40 \%$ replacement can be used for durability improvement.

\section{ACKNOWLEDGEMENT}

This work was financially supported by the UAEU-UPAR2 Research Grant \# 31N2018. Also, the donation of the ceramic waste powder for the study by PORCELLAN (ICAD II MUSSAFAH - ABU DHABI) and the cooperation of Eng. Mostafa Gad Alla and Mr. Dilip Kumar Borah are highly appreciated.

\section{REFERENCES}

Halicka, A., et al. (2013). "Using ceramic sanitary ware waste as concrete aggregate." Construction and Building Materials, 48, 295-305.

Najim, K. B., et al. (2016). "Characterization of sustainable high performance/self-compacting concrete produced using CKD as a cement replacement material." Construction and Building Materials, 103, 123-129.

Rahhal, V., et al. (2014). "Utilization of ceramic wastes as replacement of portland cements." International Conference on Construction Materials and Structures (ICCMATS), S.O. Ekolu et al. (Eds.), IOX Press, Johannesburg, South Africa, Nov. 24-26, 208-213.

Sadek, D. M., et al. (2014). "Blended cement utilizing ceramic wall tiles waste." International Conference on Construction Materials and Structures (ICCMATS), S.O. Ekolu et al. (Eds.), IOX Press, Johannesburg, South Africa, Nov. 24-26, 152-161. 